\title{
“Needle-in-Groove" Technique: A Safer Modification for Subcutaneous Lateral Internal Sphincterotomy (SLIS)
}

\author{
Zahoor A. Naikoo1*, Tufale A. Dass ${ }^{1}$, Surraya I. Parray², Aijaz A. Rather ${ }^{1}$, \\ Mehmood A. Wani ${ }^{1}$ \\ ${ }^{1}$ Department of Surgery, SKIMS and Associated Hospitals, Srinagar, India \\ ${ }^{2}$ Department of Ophthalmology, Shri Maharaja Hari Singh (SMHS) Hospital, Srinagar, India \\ Email: ${ }^{\text {drahmedzahoor@gmail.com }}$
}

Received 8 April 2014; revised 17 May 2014; accepted 19 June 2014

Copyright (C) 2014 by authors and OALib.

This work is licensed under the Creative Commons Attribution International License (CC BY). http://creativecommons.org/licenses/by/4.0/

(c) (i) Open Access

\begin{abstract}
Background: Anal fissure is one of the most common and painful proctologic diseases. An anal fissure is a split in the mucosa extending from the anal verge towards the dentate line. All methods of treatment aim to reduce the anal sphincter spasm associated with chronic anal fissures. Lateral internal sphincterotomy remains the surgical treatment of choice for many practitioners. Although sphincterotomy is very successful at healing these fissures it requires an operation with associated morbidity. Aim: We present a modification of subcutaneous lateral internal sphincterotomy (SLIS) which ensures that the blade is introduced through the proper plane over a preplaced guiding needle and seems to improve the safety without compromising the efficacy of the procedure. Material and Methods: This was a prospective study conducted in a teaching hospital over a period of four years in patients with chronic anal fissures. After an informed consent all procedures were done under local anesthesia as office procedure. Patients were followed up as at 6 weeks, 3 months, 6 months and a year after procedure and assessed for relief in symptoms, healing of fissure or any incontinence. Results: One hundred and fifty-six patients underwent the procedure. Significant symptom relief was reported in all patients with overall fissure healing rate of $98.5 \%$. Recurrence of fissure within 1 year of follow up was seen in 3 patients. Most of the complications in our study were minor. Two of our patients reported new onset incontinence to flatus on first follow up which resolved within 6 months.
\end{abstract}

\section{Keywords}

Anal Fissure, Sphincterotomy, Fecal Incontinence, Internal Sphincter

\footnotetext{
${ }^{*}$ Corresponding author.
}

How to cite this paper: Naikoo, Z.A., Dass, T.A., Parray, S.I., Rather, A.A. and Wani, M.A. (2014) "Needle-in-Groove" Technique: A Safer Modification for Subcutaneous Lateral Internal Sphincterotomy (SLIS). Open Access Library Journal, 1: e510. 


\section{Introduction}

Anal fissure is a longitudinal split of the anal canal mucosa and anoderm, extending usually from dentate line to the external verge of the anal canal and was recognized as a clinical entity in 1934 [1]. The cause of anal fissure is controversial although it has been recognized that anal fissures are probably caused by internal anal sphincter hypertonia [2] [3] which causes ischemia of posterior commissure of the anus. Chronic anal fissure is the most common cause of anal pain associated with internal anal sphincter hypertonia. Reduction of hypertonia favors fissure healing and a temporary reduction in sphincter tone can be achieved by conservative treatment. A great variety of therapeutic methods for the treatment of chronic anal fissure have been proposed including non-surgical treatments, as topical treatments such as botulinum toxin, nitrate preparations and nifedipine; and surgical treatments such as anal dilatation, sphincterotomy, and advancement flap when conservative treatment fails. Surgical sphincterotomy achieves permanent reduction of sphincter hypertonia and is very successful at healing anal fissures, but requires an operation with associated small morbidity. Despite refinements in the technique by surgeons over the previous decades, its potential for causing fecal incontinence still persists [3]. Due to the relative difficulty in identifying the sphincter and lesser relaxation of the perineum, the portion of the internal anal sphincter divided tends to be variable. We have attempted to introduce a modification to the conventional technique in subcutaneous lateral internal sphincterotomy (SLIS) making the identification of internal sphincter easier and rendering the procedure simpler to perform and convenient for the patient with reproducibility of results. "Needle-in-Groove" modification of SLIS ensures that the blade is introduced through the proper plane over a pre-placed guiding needle and seems to improve the safety without compromising the efficacy of the procedure.

\section{Methods}

This prospective study was conducted at teaching hospital over a period of four years (2006-2010). All patients subjected to the procedure were fulfilling the following three criteria:

1) Had failed 6 weeks conservative trial.

2) Had anal fissure with at least one of the these features of chronicity viz, visible sphincteric muscle at the base of papilla, sentinel pile or hypertrophied papilla.

3) Had discernable intersphincteric groove.

Patients with previous history of ano-rectal surgery or radiotherapy, indistinct intersphincteric groove, Crohn's disease, morbid obesity, significant ankylosis of hip or knee were excluded from the study group. Informed consent was taken from all patients.

Technique of "Needle-in-Groove" SLIS: All cases were done under local anesthetic.

a) Patients were kept in Sim's position and adhesive strapping was used to keep the bulk of buttocks from falling on to the perianal area.

b) Digital rectal examination was done using Lignocaine jelly and intersphincteric groove was palpated.

c) After confirming the distinction of the groove a long needle of $20 \mathrm{G}$ (Win Medikit) was introduced at the lateral margin of anal canal into the intersphincteric plane (Figure 1).

d) Left index finger, lubricated with $2 \%$ xylocaine jelly was used to confirm that the needle would stand out sub-anodermally, at least upto the dentate line, on $30^{\circ}$ lateral tilt.

e) Local anesthetic agent (2\% xylocaine) was infilterated around the pre-placed needle and an 11 size surgical blade was used to slide over the pre-placed needle into the intersphincteric plane.

f) The needle was removed and the blade was rotated by $90^{\circ}$ with the sharp edge facing towards the lumen of anal canal. Rest of the procedure was accomplished on conventional lines with the index finger inside the anal canal used to apply gentle pressure on the inner sphincteric muscle to aid sphincterotomy.

While cutting the internal sphincter we intent to undercut than over cut (The procedure is shown in pictures; Figures 2-4). Post operatively patients were observed for two hours and examined before being sent home with advice to report in case of bleed, excessive pain or swelling at the site of procedure. Patients were followed up at 1 week, 6 weeks, 3 months, 6 months and 1 year. We collected information on symptoms, bowel habits, 


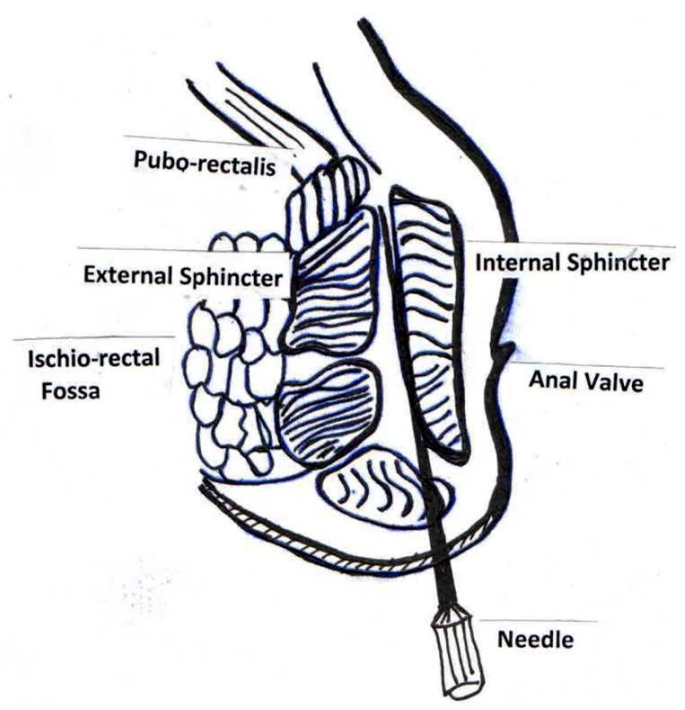

Figure 1. Line diagram showing placement of needle in the groove between external sphincter complex and internal sphincter.

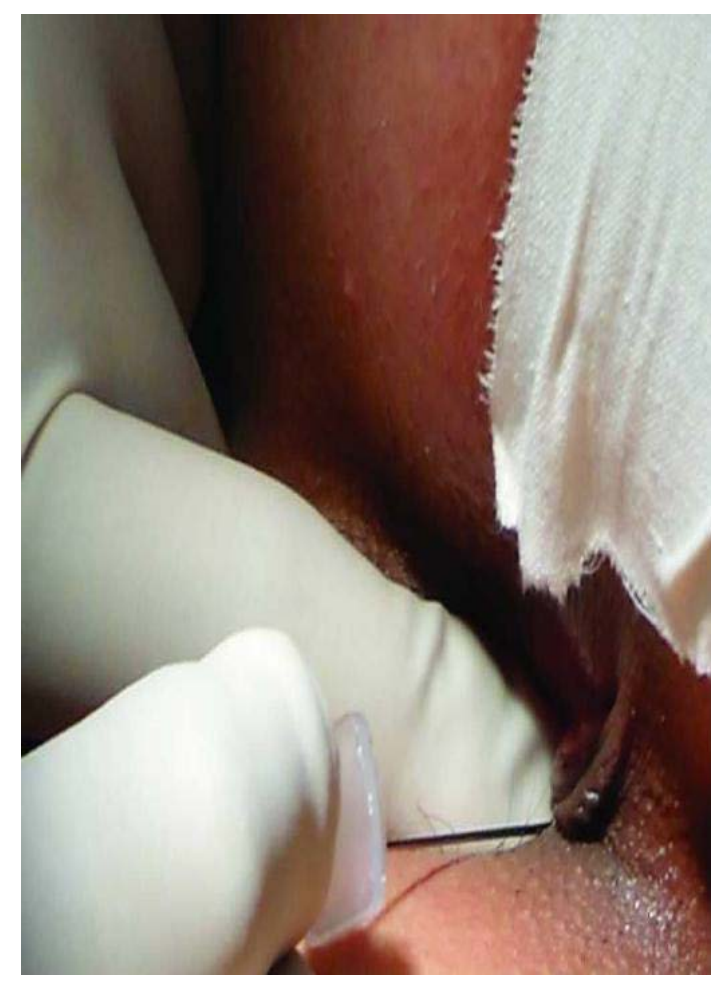

Figure 2. Needle being introduced into intersphincteric groove.

findings on examination, early and late complications, healing, and fissure recurrence. Healing was defined as an epithelization of the fissure with absence of symptoms. Continence was determined using Wexner scoring system [4]. The resultant data of the study was analyzed using standard statistical analysis.

\section{Results}

Out of total 156 patients who underwent this procedure, 17 patients were lost to follow up and were excluded from the final analysis. The mean age of patients in our study was 32 years with a male to female ratio of 2:1. Of 


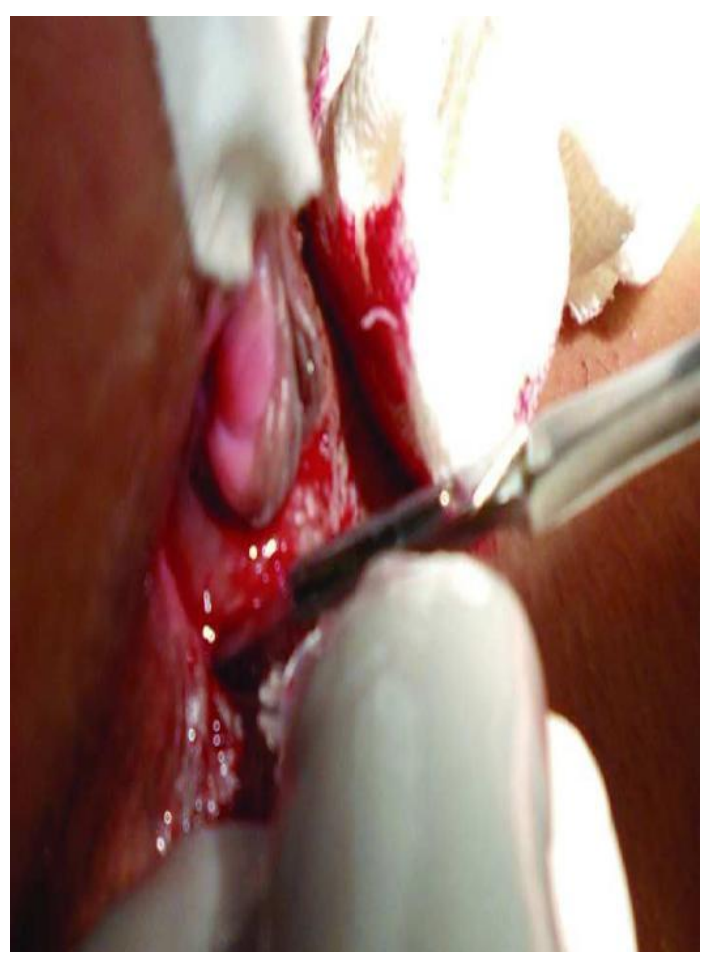

Figure 3. No. 11 size blade being introduced, guided by the needle.

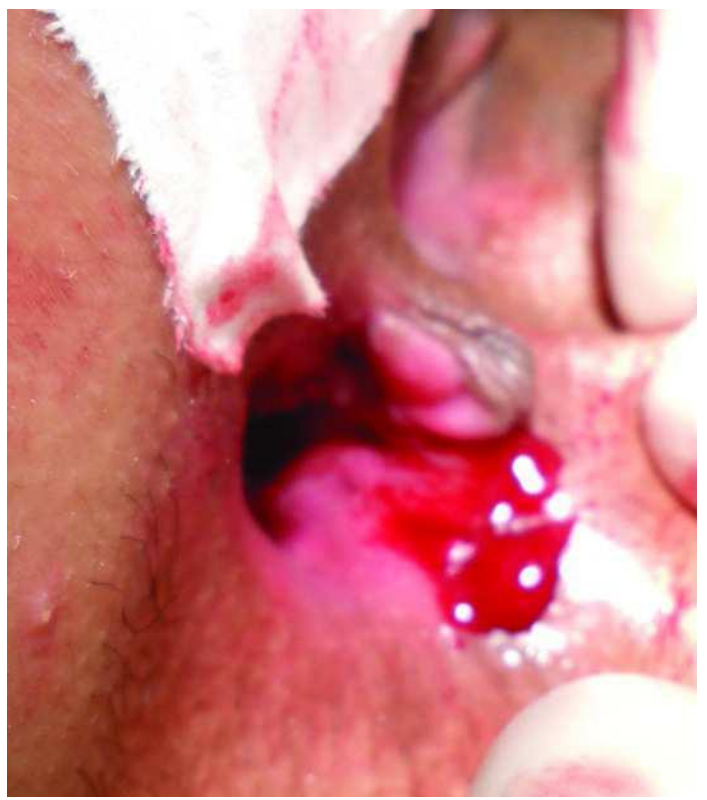

Figure 4. Final result.

the 139 patients, 118 had a posterior midline fissure while 21 patients had an anterior midline fissure. Patient characteristics are given in Table 1 . We documented an overall fissure healing rate of 98.5\% (137 of 139), with a great majority (129 of 137) having healed at 6weeks only. In the other two patients a significant decrease in symptom severity was noted. In immediate post operative period fissure associated pain and bleeding was reduced in all of the patients. Complications in our study were minor, comprised of localized hematoma formation in 4 patients, anorectal abscess formation in 1 patient, post operative urinary retention in 1 patient. Recurrence of fissure within 1 year of follow up was seen in 3 patients (2.1\%). Two of our patients reported new onset in- 
Table 1. Symptom profile and findings at examination in the study group patient characteristics $(n=139)$.

\begin{tabular}{cc} 
Age (y) & $32 \pm 5.23$ \\
Male:female ratio & $2.08: 1$ \\
Duration of symptoms (m) mean (SD) & $2.0 \pm 2.1$ \\
Posterior:anterior fissure & $5.6: 1$ \\
Bleeding & $121(87 \%)$ \\
Constipation & $108(77.6 \%)$ \\
Pain & $132(94.9 \%)$ \\
Visible sphincteric muscle & $80(57.5 \%)$ \\
Sentinel pile & $90(64.7 \%)$ \\
Sphincteric spasm & \\
Mild & $25(17.9 \%)$ \\
Moderate & $70(50.3 \%)$ \\
Severe & $44(31.6 \%)$ \\
\hline
\end{tabular}

continence to flatus on first follow up at seventh post operative day however the incontinence resolved in both patients within 6 months.

\section{Discussion}

Anal fissure is a longitudinal ulcer in anoderm extending from anal margin to dentate line and is usually attributed to passage of large hard stools. It can develop after acute episodes of diarrhea and bowel wall infection [5]. Though chronic anal fissure lacks universal definition but most of the authors believe that a fissure with fibrous induration or with exposed internal sphincter at the base that has failed to heal with 6 weeks conservative trial should be considered chronic [6]. Non healing of the ulcer is believed to result from compromised perfusion to the anoderm in posterior midline by reactive sphincteric spasm. Increase in resting anal pressure is documented in patients with chronic anal fissure, which exceeds $30 \mathrm{mmHg}$ or more when compared with healthy controls and is associated with decrease in posterior anal blood flow [7] [8]. It explains how surgery by disrupting the internal anal sphincter decreases the anal tone and improves anoderm blood flow allowing the fissure to heal [5]. Classical sites of fissures are posterior midline and anterior midline. Atypical fissures are off the midline, large, irregular or multiple. They are usually associated with inflammatory bowel disease, local or systemic malignancy, venereal infection, tuberculosis, trauma or chemotherapy and are unlikely to resolve with conservative measures [9]. Anal fissures with features of chronicity are unlikely to heal with conservative management [9] [10]. Surgical means of curing the condition aim at reducing the anal canal pressure by eliminating the sphincter spasm. Commonly used operative procedures for the condition are subcutaneous lateral internal sphincterotomy, described by Notaras in 1969 and Lord's anal dilatation [11]. High cure and low recurrence rates are achieved with surgery [9] [12]. Lateral internal sphincterotomy is the most commonly used operative technique, which is highly efficient and succeeds in curing the fissure in $90 \%-100 \%$ of the patients [13]-[15]. We documented an overall cure rate of $98.5 \%$ with our modified technique for SILS, which compares favorably with the published data.

Advantages of "Needle-in-Groove" technique over the conventional SLIS include:

1) It utilizes the distinction of the groove before infiltration of local anesthesia for securing the proper intersphincteric plane.

2) In view of the less traumatic nature of needle as compared to blade the potential for causing sphincteric damage is avoided if more than one attempt is needed, to enter the intersphincteric plane (especially for beginners).

3) Securing proper plane with a less traumatic needle avoids apprehensions which otherwise are inevitable while the surgeon introduces the cutting blade in an unguided plane. And thereby our modification is expected to 
decrease the hesitancy on the part of the surgeon.

4) May prove helpful, in future by using specific needle and blades with markings, in standardizing the procedure with regards to proportion of sphincter to be incised.

The fundamental drawback of SLIS is its potential to cause gas, mucus or occasional stool incontinence which can be permanent in $8 \%$ - 30\% of patients and it may be associated with abscess formation and deformity [5] [16]. The wide range of discrepancies in published rates of post sphincterotomy incontinence and recurrence have been attributed to many factors viz lack of standardization of the procedure in terms of proportion of sphincter sacrificed, varied patient inclusion criteria, variable post operative follow up of the patients and variable means of assessing type and frequency of incontinence [17]. On systemic review of randomized surgical trials the overall risk of post operative incontinence is about $10 \%$ and this is mostly incontinence to gas, while there are no reports delineating the duration of this problem (whether it is permanent or transitory) [13] [18] [19]. With our "Needle-in-Groove" technique there were no cases of incontinence at one year follow up. However 2 of 139 patients (1.4\%) had new onset incontinence for flatus which resolved within six months. Such spontaneous resolution reflects the healing of sphincterotomy as was proved by Edward Ram et al., in their long term manometric study of internal anal sphincter function in patients who underwent SLIS [20]. Their study documented that during the first year following surgery, the tone of the internal anal sphincter gradually increased, showing recovery, but still remained significantly lower than before surgery. However such decrease in anal sphincteric pressure may not be clinically significant because none of the patients suffered permanent incontinence [20]. The low rate of incontinence in our patients could be attributed to our propensity to undercut the sphincter; in this regard the amount of pressure applied by the finger inside the anal canal is of paramount importance. We had very low incidence of other minor complications associated with the procedure including hematoma formation in $2.8 \%$, anorectal abscess formation and urinary retention in less than $1 \%$ of patients. Recurrence rates of $0 \%-10 \%$ have been published in the literature following lateral internal sphincteromy [19] [21]-[23]. We documented low recurrence of $2 \%$ in our study with a follow-up of one year. Manometric studies have found that patients with recurrent fissure have mean resting pressure quite high than controls. Arroyo et al. in their prospective long term study documented postoperative mean resting pressure (112.9 $\mathrm{mmHg}$ ) similar to the preoperative mean resting pressure $(113.9 \mathrm{mmHg})$ in patient with recurrence of the fissure which was quite contrary to the group who healed, where post-operative mean resting pressure $(75.65 \mathrm{mmHg}$ ) was reduced by $34 \%$ [17].

In our study above mentioned advantages of needle-in-groove technique do translate into improving the safety of the procedure without compromising its effectiveness. This technique has the added advantage of not requiring hospital admission, an operating theatre, or preoperative studies. Moreover, the lower morbidity associated with local anesthesia as compared to general or spinal anesthesia gives the patient a higher degree of satisfaction and comfort. Larger studies with a longer follow up are required to further consolidate these findings.

\section{Conclusion}

Surgical sphincterotomy always had the status of being most effective modality for anal fissures particularly in the chronic variety. But, the inherent risk of causing fecal incontinence always plagued its popularity. We introduce a new modification for SLIS and more refined patient selection criteria for the procedure in order to make the procedure more convenient and safe for the surgeon. In a properly selected patient "Needle-in-Groove" modification which ensures that the blade is introduced through the proper inter-sphincteric plane over a preplaced guiding needle (before infiltration of local anesthetic) can realize the dream of safety of SLIS without compromising its effectiveness. In addition it can be used as a very safe alternative to the conventional technique while training young surgeons interested in ano-rectal disease management.

\section{Conflicts of Interests}

No conflict of interest to be declared by the authors.

\section{References}

[1] Dziki, A., Trzcinski, R., Langer, E. and Wronski, W. (2002) New Approaches to the Treatment of Anal Fissure. Acta Chirurgica Iugoslavica, 49, 73-75. http://dx.doi.org/10.2298/ACI0202073D

[2] Bove, A., Balzano, A., Parotti, P., Antropoli, C., Lombardi, G. and Pucciaini, F. (2004) Different Anal Pressure Pro- 
files in Patients with Anal Fissure. Techniques in Coloproctology, 8, 151-156.

http://dx.doi.org/10.1007/s10151-004-0079-z

[3] Ammari, F.F. and Bani-Hani, K.E. (2004) Fecal Incontinence in Patients with Anal Fissure: A Consequence of Internal Sphincterotomy or a Feature of the Condition. Surgeon, 2, 225-229. http://dx.doi.org/10.1016/S1479-666X(04)80005-2

[4] Jorge, J.M.N. and Wexner, S.D. (1993) Etiology and Management of Fecal Incontinence. Diseases of the Colon \& Rectum, 36, 77-97. http://dx.doi.org/10.1007/BF02050307

[5] Lund, J.N. and Scholefield, J.H. (1996) Etiology and Treatment of Anal Fissure. British Journal of Surgery, 83, 13351344. http://dx.doi.org/10.1002/bjs.1800831006

[6] Bhardwaj, R. and Parker, M.C. (2007) Modern Perspectives in the Treatment of Chronic Anal Fissures. Annals of the Royal College of Surgeons of England, 89, 472-478. http://dx.doi.org/10.1308/003588407X202137

[7] Schouten, W.R., Briel, W.J. and Auwerda, J.J. (1994) Relationship between Anal Pressure and Anodermal Blood Flow. The Vascular Pathogenesis of Anal Fissures. Diseases of the Colon \& Rectum, 37, 664-669. http://dx.doi.org/10.1007/BF02054409

[8] Schouten, W.R., Briel, W.J., Auwerda, J.J. and de Graff, E.J. (1996) Ischemic Nature of Anal Fissure. British Journal of Surgery, 83, 63-65. http://dx.doi.org/10.1002/bjs.1800830120

[9] McCallion, K. and Gardiner, K.R. (2001) Progress in the Understanding and Treatment of Chronic Anal Fissure. Journal of Postgraduate Medicine, 77, 753-758. http://dx.doi.org/10.1136/pmj.77.914.753

[10] Gupta, P.J. (2004) A Study of Hypertrophied Anal Papilla and Fibrous Polyps Associated with Chronic Anal Fissure. Romanian Journal of Gastroenterology, 13, 103-107.

[11] Notaras, M.J. (1969) Lateral Subcutaneous Sphincterotomy for Anal Fissure-A New Technique. Proceedings of Royal Society of Medicine, 62, 713.

[12] Lindsey, I., Jones, O.M., Cunnighum, C. and Mortensen, N.J. (2004) Chronic Anal Fissure. British Journal of Surgery, 91, 270-279. http://dx.doi.org/10.1002/bjs.4531

[13] Wiley, M., Day, P., Rieger, N., Stephen, J. and Moore, J. (2004) Open vs Closed Lateral Internal Sphincterotomy for Idiopathic Anal Fissure-in-Ano: A Prospective, Randomized, Controlled Trial. Diseases of the Colon \& Rectum, 47, 847-852. http://dx.doi.org/10.1007/s10350-004-0530-2

[14] Hyman, N. (2004) Incontinence after Lateral Internal Sphincterotomy: A Prospective Study and Quality of Life Assessment. Diseases of the Colon \& Rectum, 47, 35-38. http://dx.doi.org/10.1007/s10350-003-0002-0

[15] Tocchi, A., Mazzoni, G., Miccni, M., Cassini, D., Betteli, E. and Brozziti, S. (2004) Total Lateral Sphincterotomy for Anal Fissure. International Journal of Colorectal Disease, 19, 245-249. http://dx.doi.org/10.1007/s00384-003-0525-9

[16] Garcia-Anguilar, J., Belmonte Montes, C., Perez, J.J., Jensen, L., Madoff, R.D. and Wong, W.D. (1998) Incontinence after Lateral Internal Sphincterotomy: Anatomical and Functional Evaluation. Diseases of the Colon \& Rectum, 41, 423-427. http://dx.doi.org/10.1007/BF02235754

[17] Arroyo, A., Perez, F., Serrano, P., Candela, F. and Calpena, R. (2004) Open versus Closed Lateral Sphincterotomy Performed as an Outpatient Procedure under Local Anesthesia for Chronic Anal Fissure: Prospective Randomised Study of Clinical and Manometric Long Term Results. Journal of the American College of Surgeons, 199, 361-367. http://dx.doi.org/10.1016/j.jamcollsurg.2004.04.016

[18] Zbar, A.P., Aslam, M. and Allgar, V. (2000) Faecal Incontinence after Internal Sphincterotomy for Anal Fissure. Techniques in Coloproctology, 4, 25-28. http://dx.doi.org/10.1007/s101510050050

[19] Nyam, D.C. and Pemberton, J.H. (1999) Long Term Results of Lateral Internal Sphincterotomy for Chronic Anal Fissure with Particular Reference to Incidence of Fecal Incontinence. Diseases of the Colon \& Rectum, 42, 1306-1310. http://dx.doi.org/10.1007/BF02234220

[20] Ram, E., Alper, D., Stein, G.Y., Bramnik, Z. and Dreznik, Z. (2005) Internal Anal Sphincter Function Following Internal Lateral Sphincterotomy for Anal Fissure: A Long Term Manometric Study. Annals of Surgery, 242, 208-211. http://dx.doi.org/10.1097/01.sla.0000171036.39886.fa

[21] Nelson, R.L. (1999) Meta Analysis of Operative Techniques for Fissure in Ano. Diseases of the Colon \& Rectum, 42, 1424-1428. http://dx.doi.org/10.1007/BF02235041

[22] Garcia-Aguilar, J., Belmonte, C., Wong, W.D., Goldberg, S.M. and Madoff, R.D. (1996) Open versus Closed Sphincterotomy for Chronic Anal Fissure: Long Term Results. Diseases of the Colon \& Rectum, 39, 440-443. http://dx.doi.org/10.1007/BF02054061

[23] Collins, E.E. and Lund, J.N. (2007) A Review of Chronic Anal Fissure Management. Techniques in Coloproctology, 11, 209-223. http://dx.doi.org/10.1007/s10151-007-0355-9 